\title{
Nasal closure for severe hereditary haemorrhagic telangiectasia in 100 patients. The Lund modification of the Young's procedure: a 22-year experience*
}

\author{
Valerie J. Lund', Yvonne Darby', Joanne Rimmer ${ }^{2,3}$, Mohammed Amin ${ }^{4}$, \\ Salina Husain ${ }^{5}$ \\ Rhinology 55: 135-141, 2017 \\ https:://doi.org/10.4193/Rhino16.315 \\ ' Royal National Throat Nose \& Ear Hospital, London, United Kingdom \\ *Received for publication: \\ 2 Department of Otolaryngology Head \& Neck Surgery, Monash Health, Melbourne, Australia \\ October 31, 2016 \\ ${ }^{3}$ Department of Surgery, Monash University, Melbourne, Australia \\ Accepted: December 11, 2016 \\ ${ }^{4}$ Mater Hospital, Dublin, Ireland \\ The National University of Malaysia, Kuala Lumpur, Malaysia
}

\begin{abstract}
Introduction: Hereditary haemorrhagic telangiectasia (HHT) is an autosomal dominant vascular disease characterized by recurrent epistaxis, mucocutaneous telangiectasia and visceral arteriovenous malformations. The nosebleeds can be life-threatening and in these circumstances, radical treatment is required.
\end{abstract}

Methods: Since 1994, closure of the nose has been undertaken to prevent severe nasal bleeding in patients meeting specific selection criteria. Outcome data collected on this cohort pre- and post-operatively is available for analysis.

Results: From a cohort of $515 \mathrm{HHT}$ patients, 100 have undergone nasal closure, bilateral ab initio in $81 \%$. Fifty patients completed pre- and post-operative epistaxis severity questionnaires and provided information on post-operative problems and 28 completed a Glasgow Benefit Inventory (GBI). Overall most patients derived significant benefit from the procedure with complete cessation of nasal bleeding in 94\%, a highly significant improvement in the epistaxis score and a mean GBI score of 53.4. Loss of smell and taste was the most frequent post-operative complaint.

Conclusion: HHT can be associated with life-threatening epistaxis significantly affecting patients' quality of life. Permanent prevention of airflow is associated with complete or near-total cessation of epistaxis in the majority of patients.

Key words: epistaxis, hereditary haemorrhagic telangiectasia, nasal closure

\section{Introduction}

Hereditary haemorrhagic telangiectasia (HHT), also known as Osler-Weber-Rendu syndrome, is an autosomal dominant vascular disease ${ }^{(1)}$. The incidence of HHT is approximately 1:5000, although there is some geographical variation ${ }^{(2)}$. It is characterized by telangiectasia throughout the body which in the nose result in recurrent epistaxis of varying severity in most of those affected. In addition, visceral arteriovenous malformations (AVMs) may occur in the lung, liver, brain or gastrointestinal tract. The telangiectasia have a structural deficiency in the tunica media, rendering them fragile and compromising their ability to vasoconstrict when damaged. Such is their fragility that bleeding can result from any activity, including drinking or eating, changes in humidity and temperature and patients often cite stress as a provoking factor. Most patients start having nosebleeds in childhood or late teens but they may begin quite late in life. The severity of the bleeding can range from mild to life-threatening and the majority of patients report an increase in bleeding as they age, though this may reflect other cardiovascular changes. This, combined with the associated anaemia, has an obvious adverse effect on quality of life ${ }^{(3)}$.

Spontaneous and recurrent epistaxis and the presence of multiple mucocutaneous telangiectasia at characteristic sites such 
as the nose are two of the four criteria required by the Curacao International Consensus Guidelines to diagnose the condition ${ }^{(4)}$.

The management of epistaxis in $\mathrm{HHT}$ primarily aims to reduce the frequency and severity of the bleeding by a variety of strategies which may need to be repeated as new telangiectasia form ${ }^{(5)}$. This may include coagulating laser eg argon or KTP, septodermoplasty, hormone manipulation eg tamoxifen, clotting manipulation eg tranexamic acid and more recently vascular formation manipulation eg bevacizumab. However, some patients have epistaxes which are so severe and so frequent so as to be life-threatening and it was for this group of patients that nasal closure was developed in the early 1990's ${ }^{(6,7)}$.

\section{Materials and methods}

Closure of the nasal cavity has been undertaken in HHT patients with severe epistaxis by the senior author since 1994. All patients fulfilled the Curacao diagnostic criteria for HHT. All those who required regular or frequent blood transfusions as a result of this bleeding, who were bleeding on a daily or near-daily basis and whose bleeding was profuse (as judged by the patient to soak a towel or require a receptacle for the blood) were offered the operation. All those who accepted underwent closure by the senior author, either bilateral or occasionally unilateral if one side was much worse and there was no pre-existing septal perforation.

Patients have been kept under regular review by telephone or post, as outpatient attendance post-closure is rarely required. The severity and frequency of the bleeding and the need for blood transfusions was noted pre- and post-operatively using a questionnaire, either that published by Al-Deen and BachmannHarildstad ${ }^{(8)}$ or one which included this information prior to 2008 , each providing a maximum score of 10 (Table 1). Patients were asked to rate their bleeding overall as none, mild, moderate or severe before and after the surgery. They were also asked about any problems experienced since the closure from a list of possible options (Table 2). In addition, the Glasgow Benefit Inventory (GBI), a validated questionnaire designed to assess how a specific intervention has altered the quality of life of a person (9), was completed post-operatively. Finally they were asked if they would be prepared to undergo the procedure again and whether they would recommend it to another patient in the same situation.

\section{Statistical analysis}

Analyses were conducted using SPSS Version 23. Descriptive statistics were generated for all demographic and scale variables. Due to the non-normal distribution of scores, non-parametric tests were utilised for all comparisons. Mann-Whitney $U$ tests were conducted to compare bleeding and GBI scores for males
Table 1. Epistaxis grading scale: observation of intensity and frequency of bleeds and blood transfusion during a period of 4 weeks ${ }^{(8)}$.

\begin{tabular}{|c|c|c|c|c|c|}
\hline \multicolumn{2}{|c|}{$\begin{array}{c}\text { Intensity of the } \\
\text { bleeds (I) }\end{array}$} & \multicolumn{2}{|c|}{$\begin{array}{l}\text { Frequency of the } \\
\text { bleeds (F) }\end{array}$} & \multicolumn{2}{|c|}{$\begin{array}{l}\text { Blood transfusion } \\
\text { (T) }\end{array}$} \\
\hline 0 & None & 0 & None & 0 & None \\
\hline 1 & $\begin{array}{l}\text { Slight stains } \\
\text { on the } \\
\text { handkerchief }\end{array}$ & 1 & $\begin{array}{l}1-5 \text { times/ } \\
4 \text { weeks }\end{array}$ & 1 & Once \\
\hline 2 & $\begin{array}{l}\text { Soaked } \\
\text { handkerchief }\end{array}$ & 2 & $\begin{array}{l}6-10 \text { times/ } \\
4 \text { weeks }\end{array}$ & 2 & $\begin{array}{l}\text { More than } \\
\text { once }\end{array}$ \\
\hline 3 & Soaked towel & 3 & $\begin{array}{l}11-29 \text { times/ } \\
4 \text { weeks }\end{array}$ & & \\
\hline 4 & $\begin{array}{l}\text { Bowl or } \\
\text { similar vessel } \\
\text { is necessary }\end{array}$ & 4 & Daily bleeding & & \\
\hline
\end{tabular}

Table 2. Problems experienced post-nasal closure* $(n=50)$.

\begin{tabular}{|l|l|}
\hline Symptom & $\%$ \\
\hline Decrease in sense of smell or taste & 40 \\
\hline Fatigue & 14 \\
\hline Nasal obstruction & 14 \\
\hline Embarrassment & 12 \\
\hline Sleep disturbance & 12 \\
\hline Ear fullness or pain & 10 \\
\hline Dry mouth & 10 \\
\hline
\end{tabular}

${ }^{*}$ several problems experienced by some individuals

and females, and between age groups split at the median (63 years).

A Wilcoxon Signed Rank test was conducted to compare preoperative and post-operative bleeding scores. An effect size was calculated using the formula $\mathrm{r}=\mathrm{z} /$ square root of $\mathrm{N}$ (Pallant, 2016) and Cohen's (1988) criteria was used to evaluate the size of the effect ( $0.1=$ small effect, $0.3=$ medium effect, $0.5=$ =large effect).

A Chi square test for independence (with Yates' Continuity Correction) was conducted to compare those who did, versus did not, complete the GBI. A Mann-Whitney U test was used to check that GBI scores did not differ as a result of time since surgery, comparing two groups split at the median time since surgery ( 3 years).

\section{Technique}

The technique has been described in detail on several occasions ${ }^{(6,10)}$. It is a modification by the senior author of the opera- 


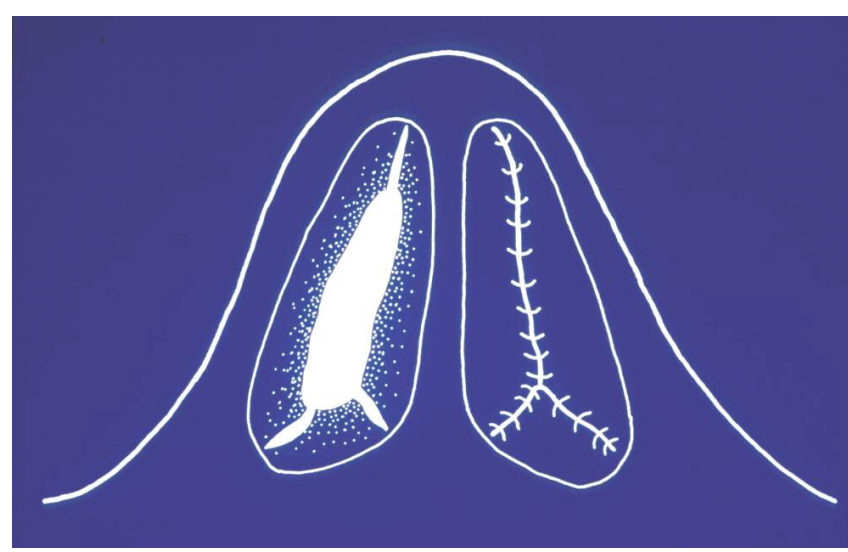

Figure 1. Diagram showing incisions for nasal closure. (With permission of Rhinology. Figure 6 from Rimmer J, Lund VJ. Hereditary haemorrhagic telangiectasia - a review. Rhinology 2015; 53: 129-134).

tion described by Young in 1967 for the treatment of primary atrophic rhinitis ${ }^{(11)}$. Young's procedure has the disadvantage of leaving a small opening at both the top and bottom of the closure through which air can enter, thereby perpetuating the bleeding, as experienced by the first HHT patient undergoing the operation in 1993. Since then, a 3 flap closure has been undertaken using a circumferential incision at the mucocutaneous junction in the nasal vestibule from which flaps are raised retrogradely after incisions at 4, 8 and 12 o'clock to the nasal rim (Figure 1). The use of temporary haemostatic agents in the nasal cavity, for example Floseal ${ }^{\mathrm{TM}}$ (a haemostatic matrix of gelatin and thrombin) or gelfoam in adrenalin, and/or a single intravenous dose of tranexamic acid (1g), plus considerable care when manipulating the nose, are employed. In two patients with extreme epistaxis, one of whom had received over 1300 blood transfusions, embolization was undertaken within 48 hours of the operation. Once closed with dissolvable sutures, the patient is discouraged from any cleaning or disturbance of the area, allowing it to heal undisturbed. The patients may also be reassured that the repair, which is initially visible, will, with the passage of a few months, retract into the vestibule and be invisible to the onlooker.

\section{Results}

One hundred patients have undergone nasal closure from an overall cohort of $525 \mathrm{HHT}$ patients managed by the senior author since the 1980 's. Sixty-one (61\%) had undergone previous treatment, either coagulating laser (58 patients) and/or septodermoplasty (30 patients), with some also taking additional oral tamoxifen (25 patients), oral medoxyprogesterone (5 patients), or high dose oral oestrogen (1 patient). All had undergone blood transfusions, some on many occasions and up to 1340 times in one patient. The follow-up ranged from 6 months to 22 years (mean 8.4yrs).
There were 51 men and 49 women, whose ages ranged from 2785 years at the time of the closure (mean 63.6 years). Eighty-one underwent bilateral closure, nineteen had a unilateral closure if one side was worse and they did not have a septal perforation which would allow air to pass into the closed side. Of these patients, six subsequently requested closure of the second side, generally within one year of the first operation. Thus 87 patients ultimately had bilateral closure.

Ten patients out of the one hundred developed small pinholes between 3 months to 5 years following the initial operation which were associated with some further bleeding (7 of the bilateral closures, 3 unilateral). Primary closure was undertaken in eight and two required nasolabial flaps which stopped the bleeding in eight of the ten patients. Of the two unsuccessful closures, one elderly patient who had had basal cell carcinomas on the external nose treated with radiotherapy and plastic surgery had a break-down of the repair which could not be successfully closed despite several attempts. The second had a persistent pinhole associated with occasional minor bleeds. In addition, six patients with bilateral closure have had one or more minor or moderate bleeds into the throat since the closure, in the absence of anterior air entry. In five this was due to the use of anti-coagulants for cardiovascular problems and in one followed trauma to the nose. One further patient requested that the nose was re-opened when he married but returned to have it reclosed 6 months later when further heavy bleeding led to marital disharmony. Thus only 8 out of the 87 patients who finally underwent bilateral closure (9\%) continued to experience any bleeding in the long term and complete cessation of epistaxis was achieved in 79 (91\%).

Pre- and post-operative epistaxis scores were available in 50 patients of the 81 who had undergone bilateral closure ab initio. There were 22 men and 28 women; age at operation was 32-84 years (mean 62 years). Pre-operative scores (done immediately prior to the operation) ranged from 8-10 (mean 9.42, standard deviation (SD) 0.76), reflecting the criteria for surgery, and all regarded their bleeding as severe. Most recent post-operative scores were obtained 0.5 to 22 years (mean 5.7 years) since the procedure (Table 3).

The post-operative scores ranged from 0-4 (mean 0.54, SD 1.05). No significant differences in bleeding scores were detected for males and females or between age groups. A Wilcoxon Signed Rank test showed a highly statistically significant change in the scores following surgery $(Z=-6.24, p<0.001)$ representing a large effect size $(r=0.88)$.

The majority (39 patients, 78\%) had experienced no further nasal bleeding at all and scored 0 . Seven had had occasional mild bleeds (as classified by the patients) in the immediate 


\begin{tabular}{|c|c|}
\hline Characteristic & Statistic \\
\hline \multicolumn{2}{|l|}{$\operatorname{Sex}(n, \%)$} \\
\hline Female & $28(56 \%)$ \\
\hline Male & $22(44 \%)$ \\
\hline \multicolumn{2}{|l|}{ Age at operation (years) } \\
\hline Mean (SD) & $62(12.09)$ \\
\hline Median (IQR: 25th, 75th) & $62.50(55.75,70)$ \\
\hline Range & $22-84$ \\
\hline \multicolumn{2}{|l|}{ Time since operation (years) } \\
\hline Mean (SD) & $5.68(6.07)$ \\
\hline Median (IQR: 25th, 75th) & $3(2,6.25)$ \\
\hline Range & $0.5-21$ \\
\hline \multicolumn{2}{|l|}{ Bleeding score $(n=50)$} \\
\hline \multicolumn{2}{|l|}{ Preoperatively } \\
\hline Mean (SD) & $9.42(0.76)$ \\
\hline Median (IQR: 25th, 75th) & $10(9,10)$ \\
\hline Range & $8-10$ \\
\hline $\begin{array}{l}\text { Mann Whitney } U \text { test comparing males } \\
\text { and females }\end{array}$ & $Z=-0.57 p=0.57$ \\
\hline $\begin{array}{l}\text { Mann Whitney U test comparing age } \\
\text { groups }\end{array}$ & $Z=-1.65 p=0.10$ \\
\hline \multicolumn{2}{|l|}{ Postoperatively } \\
\hline Mean (SD) & $0.54(1.05)$ \\
\hline Median (IQR: 25th, 75th) & $0(0,0.25)$ \\
\hline Range & $0-4$ \\
\hline $\begin{array}{l}\text { Mann Whitney } U \text { test comparing males } \\
\text { and females }\end{array}$ & $Z=-0.094 p=0.92$ \\
\hline $\begin{array}{l}\text { Mann Whitney } U \text { test comparing age } \\
\text { groups }\end{array}$ & $Z=-1.19 p=0.23$ \\
\hline \multicolumn{2}{|l|}{ GBI $(n=28)$} \\
\hline \multicolumn{2}{|l|}{ GBITotal } \\
\hline Mean (SD) & $53.43(18.11)$ \\
\hline Median (IQR: 25th, 75th) & $54.50(42,69.25)$ \\
\hline Range & $25-83$ \\
\hline $\begin{array}{l}\text { Mann Whitney } U \text { test comparing males } \\
\text { and females }\end{array}$ & $Z=-1.24 p=0.22$ \\
\hline $\begin{array}{l}\text { Mann Whitney } U \text { test comparing age } \\
\text { groups }\end{array}$ & $Z=0.28 p=0.80$ \\
\hline \multicolumn{2}{|l|}{ GBIGeneral } \\
\hline Mean (SD) & $62.43(21.90)$ \\
\hline Median (IQR: 25th, 75th) & $67(47,79)$ \\
\hline Range & $13-100$ \\
\hline $\begin{array}{l}\text { Mann Whitney } U \text { test comparing males } \\
\text { and females }\end{array}$ & $Z=1.46 p=0.14$ \\
\hline $\begin{array}{l}\text { Mann Whitney } U \text { test comparing age } \\
\text { groups }\end{array}$ & $Z=0.10 p=0.92$ \\
\hline \multicolumn{2}{|l|}{ GBI Social } \\
\hline Mean (SD) & $16.68(24.29)$ \\
\hline Median (IQR: 25th, 75th) & $0(0,17)$ \\
\hline Range & $0-83$ \\
\hline
\end{tabular}

\begin{tabular}{|lc|}
\hline Characteristic & Statistic \\
\hline $\begin{array}{l}\text { Mann Whitney U test comparing males } \\
\text { and females }\end{array}$ & $\mathrm{Z}=0.75 \mathrm{p}=0.52$ \\
\hline $\begin{array}{l}\text { Mann Whitney U test comparing age } \\
\text { groups }\end{array}$ & $\mathrm{Z}=0.20 \mathrm{p}=0.84$ \\
\hline GBI Physical & \\
\hline $\begin{array}{l}\text { Mean (SD) } \\
\text { Median (IQR: } 25 \text { th, 75th) }\end{array}$ & $33.33(36.23)$ \\
\hline $\begin{array}{l}\text { Range } \\
\text { Mann Whitney U test comparing males } \\
\text { and females }\end{array}$ & $-33-100$ \\
\hline $\begin{array}{l}\text { Mann Whitney U test comparing age } \\
\text { groups }\end{array}$ & $\mathrm{Z}=0.24 \mathrm{p}=0.82$ \\
\hline
\end{tabular}

post-operative period which ceased after 7-10 days. Four have had moderate bleeds into the throat since the operation, all due to pinholes which underwent successful revision but 3 have continued to have some intermittent post-nasal bleeding albeit less than before the closure. No patient had required a further blood transfusion since the surgery, though five had undergone laser treatment of gastro-intestinal lesions. Oral tranexamic acid (1 patient), tamoxifen (1 patient) and bevacizumab (1 patient) had been utilised in three of the 'moderate' patients with improvement. Thus three out of the fifty have continued to have some controllable nasal bleeding and 47 have achieved complete cessation (94\%).

The GBI score was obtained at the same time as the latest epistaxis score in 30 patients, but complete data was only available in 28. There were no significant differences in sex or age between those who did and did not complete the GBI. There were no significant differences in GBI scores across sex or age for those who completed it. The GBI was not influenced by the time since surgery. GBI scores ranged from 25 to 83 (mean 53.43, SD 18.11) (Figure 2). A sub-analysis of general score, physical score and social support score was also undertaken. The highest median score was recorded for the general subscore and the lowest on the social support subscore. All participants reported an improvement in general scores since their procedure. However, on the physical subscore two participants (7.1\%) recorded a decrease in scores and a further 7 (25\%) reported no change.

The most common post-operative complaint was a decreased sense of smell and taste (40\%), followed by fatigue (14\%), sleep disturbance (12\%), and ear fullness (10\%). Twelve percent mentioned embarrassment even though the closure was not usually visible. Nasal obstruction was a rather rare overt complaint (14\%) though $10 \%$ were aware of a dry mouth for which they take regular sips of water or apply lubricating gels. As a conse- 


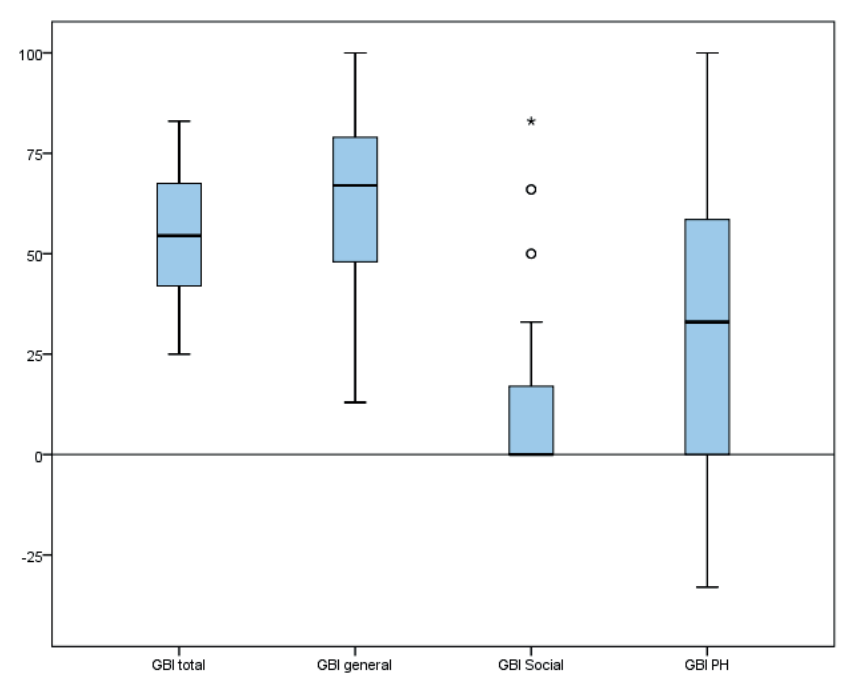

Figure 2. Boxplot showing the distribution of scores on the GBI (total and subscores).

quence of the mouth-breathing, 6 of the 87 bilateral closures (7\%) have had laser to the mouth (hard palate or tongue) on 1-3 occasions.

All patients questioned said that they would undergo the procedure again and all said that they would recommend it to another patient in similar circumstances.

\section{Discussion}

Nasal mucosal telangiectasias are very sensitive to the slightest trauma, including the passage of airflow during breathing which forms the rationale for the procedure. This was first presented by Gluckmann in the USA in 1993 and subsequently published in $1994{ }^{(12)}$, followed by another report by Hosni and Innes in the UK the same year ${ }^{(13)}$. The procedure in its modified form has been undertaken by the author since $1994{ }^{\left({ }^{(6)}\right.}$ and now constitutes the largest single centre, individual cohort worldwide, although other centres have subsequently adopted the technique.

Closure of the nose may seem an excessively radical procedure but must be seen in the context of patients who have severe life-threatening nose bleeds, requiring regular blood transfusions, and whose noses are already blocked by large amounts of clotted blood and crust. In addition, they suffer chronic debilitating anaemia and have an extremely poor quality of life ${ }^{(3,14)}$. Patients are generally well informed about their disease and will have a view as to whether they will consider this operation, often having tried other treatment options. Others, often family members or those who have had contact with fellow-sufferers through patient associations, come specifically requesting the operation. No attempt is made to persuade patients to undergo closure but they are offered contact with those who have already undergone the procedure and may be reassured that the procedure could be reversed if necessary. They can also be assured that it is safe to be a permanent obligate mouth-breather, albeit associated with some dryness of the mouth, and that the closure is cosmetically acceptable and difficult to see. However, despite this, a few cannot face the prospect of permanent mouth-breathing and will not consider the procedure.

This study confirms that the procedure is extremely effective, completely stopping the nasal bleeding in the vast majority of patients or at the very least reducing it to a tolerable level. These results have been replicated in several other centres ${ }^{(11,17-19)}$. When bleeding does occur, it is usually minor and is most often associated with pinhole breakdown of the closure, repair of which is generally successful. Although there is one case report in the literature of severe post-closure bleeding necessitating re-opening of the nose in order to control it ${ }^{(20)}$, this has not been our experience in over a hundred patients. In others, the subsequent administration of blood thinning agents for other medical conditions can produce secondary bleeding. Despite this, all patients would undergo the procedure again and all would recommend it to someone else in the same situation. Many commented that they wish they had had it done years earlier.

Consequences of the closure such as loss of smell and taste, dry mouth and sleep disturbance were elicited by direct questioning and are generally tolerated in exchange for the benefits of the procedure. Surprisingly few complained about nasal blockage per se, probably as it was an inevitable consequence of the operation. The associated dryness of the mouth may result in bleeding from lesions on the palate and tongue which are readily amenable to coagulating laser. No patient has required more than 3 treatments of the mouth.

However, the procedure requires careful patient selection; the application of strict criteria has meant that only one patient has requested and undergone re-opening, only to have it reclosed some months later. The severity of the nose bleeds does not correlate with the presence of pulmonary arteriovenous malformations ${ }^{(21)}$ but screening of the chest should be undertaken in all patients pre-operatively and arranged for every five years thereafter as once the closure has been performed, patients do not need to be seen for regular follow-up.

An early retrospective review of 12 patients who underwent nasal closure reported complete cessation of bleeding where complete closure was achieved. Previous studies have shown that quality of life can be assessed successfully using validated questionnaires such as the short-form 36 (SF-36) health-status survey as well as a disease-specific questionnaire about their epistaxis, both done pre- and postoperatively. In these, a statistically significant improvement in QOL has been previously shown in those 
who underwent nasal closure, far in excess of that experienced after coagulating laser or septodermoplasty ${ }^{(3,22)}$.

The Glasgow Benefit Inventory (GBI) is a validated patient-orientated questionnaire which was developed specifically for and to be maximally sensitive to ENT interventions ${ }^{(9)}$. The 18-item questionnaire translates into a positive, null or negative score proportional to the degree (or lack) of benefit. The number of years since the surgery has not been found to affect the overall score. It has been used to assess a wide range of operations including tonsillectomy, various otologic procedures, endoscopic sinus surgery and more recently nasal closure ${ }^{(9,17-19)}$. The mean GBI score for the following procedures has been: multichannel cochlear implantation: +49 , childhood tonsillectomy: +43 , intranasal polypectomy: +30 , endoscopic sinus surgery for CRS: +23 and middle ear operations: $+17^{(17)}$. The results from the nasal closure in this paper compare very favourably with these results, with a range of $+25-+83$ and a mean of +53.43 , making it one of the most successful operations in ENT. The lower improvement in the social support subscale is not surprising as this depends on 3 questions relating to more or less support from friends, more or less people who really care about one and more or less support from family with the highest scores being for the greater support or care post-operatively. Once the nasal bleeding is dealt with, one would expect patients to be more self-sufficient and would therefore score lower or indicate no change as actually occurred.

A recent multi-centre study has also shown improvement following nasal closure using the GBI. However, their GBI scores are not comparable to others in the literature as the methodology of the scoring system described was actually that for the Glasgow Health Status Inventory rather than the GBI and this produced higher scores than the true GBI score ${ }^{(19)}$.

Alternative treatments for this group of severe patients have included temporary closure using obturators ${ }^{(23,24)}$ but these have the significant disadvantage of potentially provoking a bleed each time they are inserted or removed. Embolisation has been used in life-threatening situations ${ }^{(25,26)}$, but has a limited and finite effect due to the 'end-organ' nature of the telangiectasia which cannot be completely ablated. However, it was used pre-operatively in two of our cases where the bleeding was so severe that surgery could not be practically undertaken without it. Similarly, the insertion of a Whitehead's varnish pack ${ }^{(27)}$ can be used to control a severe bleed whilst closure is being considered and arranged.

\section{Conclusion}

Nasal closure using the Lund modification of Young's original operation has been used with considerable success for over two decades and remains the only treatment in HHT to completely stop epistaxis. Whilst not every patient with severe epistaxis will consider it, in those that do, it is transformative and life-saving. The benefits far outweigh the small associated inconveniences and the outcome can be best summed up by sentiments frequently expressed by patients, as exemplified by the following: 'The operation is one of the best things I have ever done. Thank you so much for transforming my life - I am now able to go out and about without the constant fear of heavy nosebleeds.'

Quotation from recent patient's email

\section{Authorship contribution}

VJL: principle author, surgeon and prospective collection of data; JR: assisted composition of manuscript and undertook statistics; YD: collected data and reviewed manuscript; MA: collected data and reviewed manuscript; $\mathrm{SH}$ : collected data and reviewed manuscript.

\section{Conflict of interest}

None.

\section{References}

1. Govani FS, Shovlin CL. Hereditary haemorrhagic telangectasia: a clinical and scientific review. Eur J Hum Genet 2009; 17: 860-871

2. Shovlin CL. Hereditary haemorrhagic telangectasia: pathophysiology, diagnosis and treatment. Blood Rev 2010; 24: 203-219

3. Lennox PA, Hitchings AE, Lund VJ, et al. The SF-36 health status questionnaire in assessing patients with epistaxis secondary to hereditary hemorrhagic telangectasia. Am J Rhinol 2005; 19: 71-74

4. Faughnan ME, Palda VA, Garcia-Tsao G, et al. International guidelines for the diagnosis and management pf hereditary haemorrhagic telangectasia. J Med Genet 2011; 48: 73-87

5. Rimmer J, Lund VJ. Hereditary haemorrhag- ic telangiectasia - a review. Rhinology 2015 53: $129-134$

6. Lund VJ, Howard DJ. Closure of the nasal cavities in the treatment of refractory hereditary haemorrhagic telangectasia. J Laryngol Otol 1997; 111: 30-33

7. Lund VJ, Howard DJ. A treatment algorithm for the management of epistaxis in hereditary haemorrhagic telangectasia. Am J Rhinol 1999; 13: 319-322

8. Al-Deen S, Bachmann-Harildstad G. A grading scale for epistaxis in hereditary haemorrhagic telangiectasia. Rhinology 2008; 46 281-284

9. Robinson K, Gatehouse S, Browning GG. Measuring patient benefit from otorhinolaryngological surgery and therapy. Ann Otol Rhinol Laryngol 1996; 105: 415-422
10. Lund VJ. Nasal closure for HHT. Masters Techniques in Otolaryngology Head and Neck Surgery. Rhinology Volume. Eds: Myers E, Kennedy D. Lippincott Williams and Wilkinson 2.2015 ISBN-13: 978-1451175578

11. Young $A$. Closure of the nostrils in atrophic rhinitis. J Laryngol Otol 1967; 81: 515-524

12. Gluckman J, Portugal L. Modified Young's procedure for refractory epistaxis due to hereditary haemorrhagic telangiectasia. Laryngoscope 1994; 104: 1174-1177

13. Hosni A, Innes A. Hereditary haemorrhagic telangiectasia: Young's procedure in the management of epistaxis. J Laryngol Otol 1994; 108: 754-757

14. Loaec M, Moriniere S, Hitier M, Ferrant O, Plauchu H, Babin. Psychosocial quality of life in hereditary haemorrhagic telangiectasia. 
Rhinology 2011; 49: 164-167

15. Serrano E, Percodani J, Pessey J. La fermature bilateral des fosses nasals: une technique chirurgicale originale du traitment des epistaxis recidivantes de la maladie de Rendo-Osler. Ann Otolaryngol Chir Cervicofac 1998; 115: 169-173

16. Ichimura K, Kikuchi H, Imayoshi S, Yamauchi T, Ishikawa K. Are patients with severe epistaxis caused by hereditary haemorrhagic telangiectasia satisfied with nostri closure surgery? Auris Nasus Larynx 2012 39: 59-64

17. Mehanna H, Mills J, Kelly B, McGarry G. Benefit from endoscopic sinus surgery. Clin Otolaryngol 2002; 24: 464-471

18. Newton J, Shakeel M, Ram B. Evaluation of endoscopic sinus surgery by Glasgow Benefit Inventory. J Laryngol Otol 2008; 122: 357-360

19. Richer S, Geisthoff U, Livada N, et al. The Young's procedure for severe epistaxis from hereditary haemorrhagic telangiectasia. Am J Rhinol Allergy 2012; 26: 401-404

20. Ting J, Remenschneider A, Holbrook E. Management of severe epistaxis after
Young's procedure: a case report. IFAR 2013;3:334-337

21. Vertek M, Shovlin C, Lund V. Silent threat? A retrospective study of screening practices for pulmonary arteriovenous malformations in patients with hereditary haemorrhagic telangiectasia. Rhinology 2012; 50-3: 277 283

22. Hitchings $A E$, Lennox PA, Lund VJ, et al. The effect of treatment for epistaxis secondary to hereditary haemorrhagic telangectasia. Am J Rhinol 2005; 19: 75-78

23. Woolford T, Loke D, Bateman N. The use of a nasal obturator in Hereditary haemorrhagic telangiectasia: an alternative to Young's procedure. J Laryngol Otol 2002; 116: 455-456

24. Bruschini L, Seccia V, Dallan I. Portugal L. A silicone nasal swab for the treatment of severe and recalcitrant epistaxis in hereditary haemorrhagic telangiectasia: an alternative to surgical nostril closure. Am J Rhinol 2011; 32: 301-303

25. Braak S, de Witt C, Disch F, Overtoom T, Westermann J. Percutaneous embolisation in hereditary hemorrhagic telangiectasia patients with severe epistaxis. Rhinology
2009; 47: 166-171

26. Trojanowski P. Jargiello T, Trojanowska A et al. Epistaxis in patients with hereditary hemorrhagic telangiectasia treated with selective arterial embolization. Acta Radiol 2011; 52: 846-849

27. Lim M, Lew-Gor S, Sandhu G, Howard D, Lund V. Whitehead's Varnish nasal pack. J Laryngol Otol 2007; 121: 592-594

Professor Valerie J Lund CBE

Professorial Unit

Royal National, Throat, Nose and Ear

Hospital

330 Grays Inn Rd

London WC21X 8DA

United Kingdom

E-mail:v.lund@ucl.ac.uk 